\title{
Efficacy of prednisolone for children with acute bronchiolitis having family history of atopy: A randomized placebo-controlled trial
}

\author{
M A H Mollah ', K J Hasan², M E Rahman ${ }^{3}$, S Rahman ${ }^{4}$
}

\begin{abstract}
:
Objective : To determine the efficacy of oral prednisolone among children with acute bronchiolitis who have associated family history of atopy.

Materials and Methods : This randomized double blind placebo controlled trial was carried out in Dhaka Medical College Hospital during July'08 to June'10. A total of sixty patients (1-24 months) of acute bronchiolitis who had family history of atopy (e.g. allergic rhinitis, allergic conjunctivitis, asthma, eczema) were enrolled. After enrollment, allocation of either prednisolone or placebo to the study subjects were done randomly by lottery method and the researcher remained blind about the allocation. Finally 30 cases received prednisoloneorally at a dose of $2 \mathrm{mg} / \mathrm{kg} / \mathrm{day} 8$ hourly for 3 consecutive days and 30 cases received placebo (made of flour). In addition, both the groups got same supportive measures.

During intervention, study subjects were monitored by Modified Respiratory Distress Assessment Instrument (MRDAl) score twice daily for consecutive 3 days. Duration of oxygen therapy as well as length of hospital stay was also determined. Data were analyzed using appropriate statistical tests and a $p$ value of $<0.05$ was considered significant.
\end{abstract}

Results : The respiratory rate, accessory muscle use and auscultatory finding scores were significantly declined in Prednisolone group than the placebo group $(p<.05)$. However, cyanosis score though declined in both groups, the difference was not significant $(p>.05)$. Mean duration of oxygen therapy needed in Prednisolone group was significantly lesser than the placebo group (13.7 vs 24.1 hours; $P<.01)$. Similarly, the length of hospital stay was shorter in prednisolone group than in placebo group (3.3 vs 4.6 days; $\mathrm{p}<.01$ ).

Conclusions : Three days of oral prednisolone therapy along with supportive measures was found to be significantly useful among children with acute bronchiolitis having family history of atopy in terms of clinical recovery, oxygen requirement and duration of hospital stay.

\section{Introduction}

Bronchiolitis is a major public health problem throughout the world ${ }^{1}$. In Bangladesh a country wide survey on 5157 under 5 sick children in 42 hospitals showed that respiratory problems comprised of about $67 \%$ and out of that bronchiolitis is the most common lower respiratory illnesses among under 5 children. ${ }^{2}$ But treatment is only supportive with unpredictable outcome and high morbidity.

Around $80-90 \%$ of Bronchiolitis are due to $\mathrm{RSV}^{3} \mathrm{An}$ $\mathrm{Ig}$ - $\mathrm{E}$ mediated immune response is noted in most of the cases of RSV bronchiolitis, especially among atopy-prone children e.g. those with positive $\mathrm{H} / \mathrm{O}$ atopy among $1^{\text {st }}$ degree relatives. ${ }^{1-6}$ As Systemic steroids are effective option of treatment for atopic disorders, assuming that bronchiolitis if more severe and refractory to conventional treatment in atopyprone children is due to possible underlying immune mechanism. Therefore, it is hypothesized that children with bronchiolitis and family history of atopy may be benefited from systemic steroid in addition to other supportive measures.

\section{Materials \& Methods}

This randomized double blind placebo controlled trial was conducted in Department of Paediatrics in Dhaka Medical College Hospital (DMCH), Bangladesh from July' 2008 to June'2010. Ethical clearance was obtained from the ethical review committee of DMCH to conduct the research work.

Sample size for this study was calculated by stata software. Total 60 children between 1 month- 2 years of age, both male and female, who were hospitalized with bronchiolitis and had Family History of atopy were enrolled in this study. Informed written consent was taken from the parents or legal guardian for enrolment of their child in this study.

In this study population bronchiolitis was diagnosed clinically by presence of cough, breathing difficulty, chest indrawing and ronchi on auscultation following a viral upper respiratory catarrh. ${ }^{7}$ Family history of atopy was defined by presence of atopy of any form (asthma, allergic rhinitis, allergic conjunctivitis, eczema) in any of the $1^{\text {st }}$ degree relatives (father, mother, sister, brother). Children having recurrent attacks of wheeze with associated respiratory disorders e.g. pneumonia, pneumothorax, laryngo/ tracheomalacia, associated co-morbidities e.g. Severe Acute Malnutrition (SAM), heart failure, Down syndrome or previous history of treatment with prednisolone and/or bronchodilator were excluded from the study.

After enrollment all patients were thoroughly assessed clinically, a base line CXR and complete blood count were done.

The patients were allocated either in Prednisolone or in Placebo groups randomly by lottery, i.e. the parents or accompanying guardian picked up a sealed encoded envelop from a box of eight. Each encoded envelop contained 15 small packets of powdered prednisolone or placebo, each weighing $5 \mathrm{mg}$. The 
code was given by the guide and code numbers were recorded in a preformed questionnaire. Both the researcher and the parents remained blind about the allocation.

Out of 60 children 30 cases received prednisolone $(2 \mathrm{mg} / \mathrm{kg} /$ day) and 30 cases received same amount of placebo made of flour orally at 8 hours interval for 3 consecutive days. In addition, both groups received Oxygen, nutritional support and nebulized salbutamol \& ipratropium.

During study, patients were monitored twice daily for clinical response to therapy by modified Respiratory Distress Assessment Instrument score (mRDAl) [annex 1] for 3 consecutive days. Duration of Oxygen therapy and length of hospital stay were also documented.

\begin{tabular}{|c|c|c|c|c|}
\hline Clinical parameter & Score 0 & Score1 & Score2 & Score3 \\
\hline Respiratory rate(Breaths/Min) & $<40$ & $40-60$ & $60-70$ & $>70$ \\
\hline $\begin{array}{l}\text { Use of accessory muscle } \\
\text { Intercostal/subcostal retraction }\end{array}$ & None & Mild & Moderate & Severe \\
\hline Colour/cyanosis & $\begin{array}{l}\text { Pink in room air/ } \\
\text { No cyanosis }\end{array}$ & $\begin{array}{l}\text { Cyanosed when } \\
\text { crying }\end{array}$ & $\begin{array}{l}\text { Pink with } \mathrm{O}_{2} / \text { cyanosis } \\
\text { in room air }\end{array}$ & $\begin{array}{l}\text { Cyanosed with } \\
\text { oxygen }\end{array}$ \\
\hline Auscultatory findings & Normal & $\begin{array}{l}\text { Decreased air entry } \\
\text { no rhonchi }\end{array}$ & $\begin{array}{l}\text { Decreased air entry, } \\
\text { rhonchi heard }\end{array}$ & Silent chest \\
\hline
\end{tabular}

Ref : J M Langley et al. Racemic epinephrine compared to salbutamol in hospitalized young children with bronchiolitis; a randomized controlled clinical trial. BMC Pediatr 2005, 5 :7

Descriptive statistical analysis was done by using frequency tabulation, mean and standard deviation. Chi-square test for qualitative variables and student t-test for continuous variables were applied to determine statistical significance. Statistical significance was set at $p$ value $<0.05$ at $95 \%$ confidence interval.

\section{Result}

60 children were enrolled in this study and were treated either with prednisolone or placebo by lottery method, 30 patients in each group.

The baseline characteristics among the study (prednisolone) and control (placebo) group including age, sex, clinical presentation (fever, feeding difficulty, SpO2) and family history of atopy were statistically comparable as shown in Table I. Mean age of affection of the patients with bronchiolitis in this study was 3.68 months ( $\pm 1.295 D)$ and 3.52 months $( \pm 1.1 S D)$ in prednisolone and placebo group respectively. Though male are predominantly affected in both study and control group in this study, $53.3 \%$ and $66.7 \%$ respectively, there is no significant statistical difference in baseline characteristics among the groups.

\begin{tabular}{|c|c|c|c|}
\hline Baseline characteristics & $\begin{array}{l}\text { Study group } \\
(n=30) \text { No }(\%)\end{array}$ & $\begin{array}{l}\text { Control group } \\
(n=30) \text { No }(\%)\end{array}$ & $P$ value \\
\hline Age in months (Mean \pm SD ) & $3.68 \pm 1.29$ & $3.52 \pm 1.11$ & $P>.05$ \\
\hline \multicolumn{4}{|c|}{ Sex } \\
\hline Male & $16(53.3 \%)$ & $20(66.7 \%)$ & $P>.05$ \\
\hline Female & $14(46.7 \%)$ & $10(33.3 \%)$ & $P>.05$ \\
\hline \multicolumn{4}{|l|}{ Clinical parameters } \\
\hline Fever & $28(93.3 \%)$ & $29(96.7 \%)$ & $P>.05$ \\
\hline Feeding difficulty & $25(83.3 \%)$ & $23(76.7 \%)$ & $P>.05$ \\
\hline $\begin{array}{l}\mathrm{SPO}_{2} \\
\text { Family history of atopy }\end{array}$ & $89 \%$ & $87 \%$ & $P>.05$ \\
\hline Allergic Rhinitis & $13(43.3 \%)$ & $16(53.3 \%)$ & $P>.05$ \\
\hline Asthma & $8(26.6 \%)$ & $6(20 \%)$ & $P>.05$ \\
\hline Allergic conjunctivitis & $2(6.7 \%)$ & $1(3.3 \%)$ & $P>.05$ \\
\hline Eczema & $7(23.3 \%)$ & $7(23.3 \%)$ & $P>.05$ \\
\hline
\end{tabular}

On daily assessment of patients for clinical response to therapy by mRDAl score, respiratory rate score was found similar in both the groups on $1^{\text {st }}$ day $(p>0.05)$ but next two days of assessment revealed significant difference with better response in prednisolone group $(p<0.01)$ [Table II]. Similar result was seen in terms of use of accessory muscle score and auscultatory finding score where there was no difference in response between study and control group on $1^{\text {st }}$ day of assessment ( $p>0.05$ ) but better response was observedin prednisolene group on next 2 consecutive days $(p<0.01)$ [Table III \& IV].

While assessing the cyanosis score no difference was found on response to treatment in two groups on 3 days of assessment ( $p>0.05$ ) [Table V]

\section{Table II : Efficacy of prednisolone in terms of respiratory rate score}

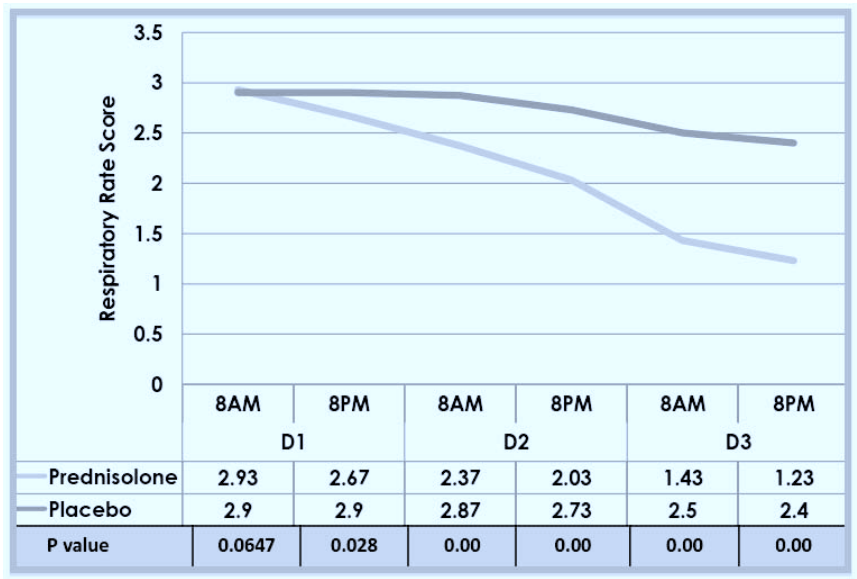

Table III : Efficacy of prednisolone in terms of use of accessory muscle score

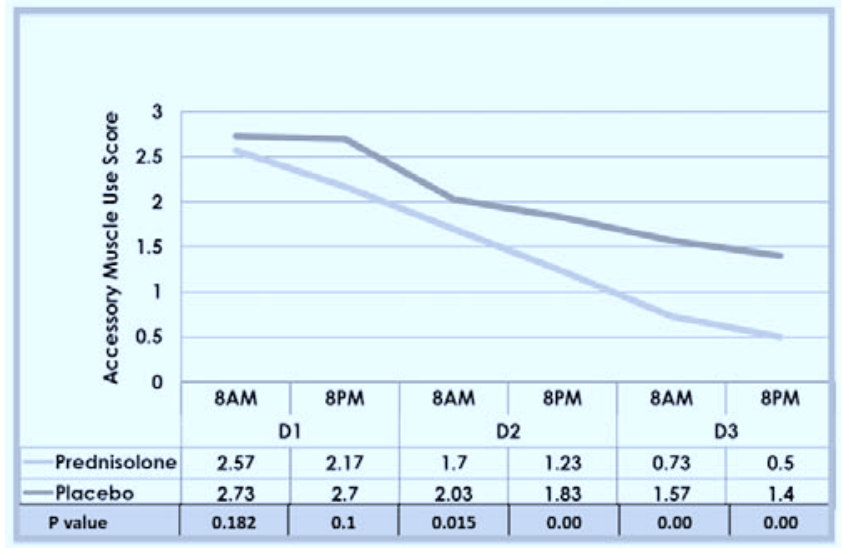

Table IV : Efficacy of prednisolone in terms of auscultatory finding

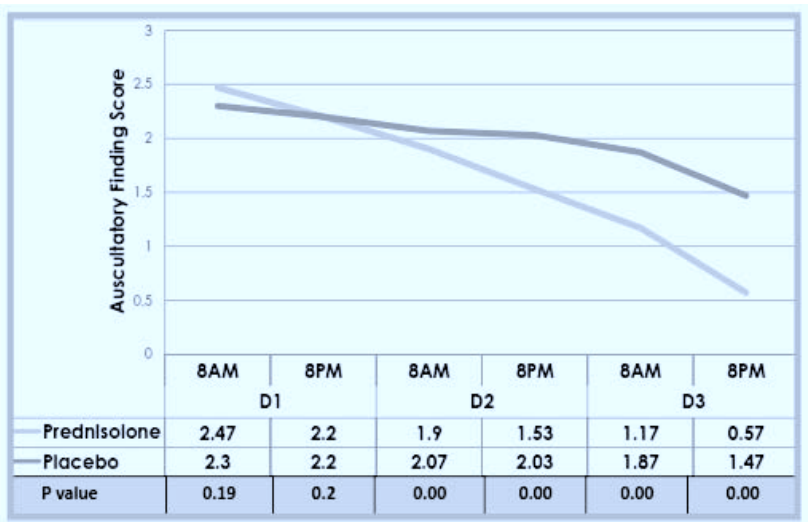


Table V: Efficacy of prednisolone in terms of cyanosis score

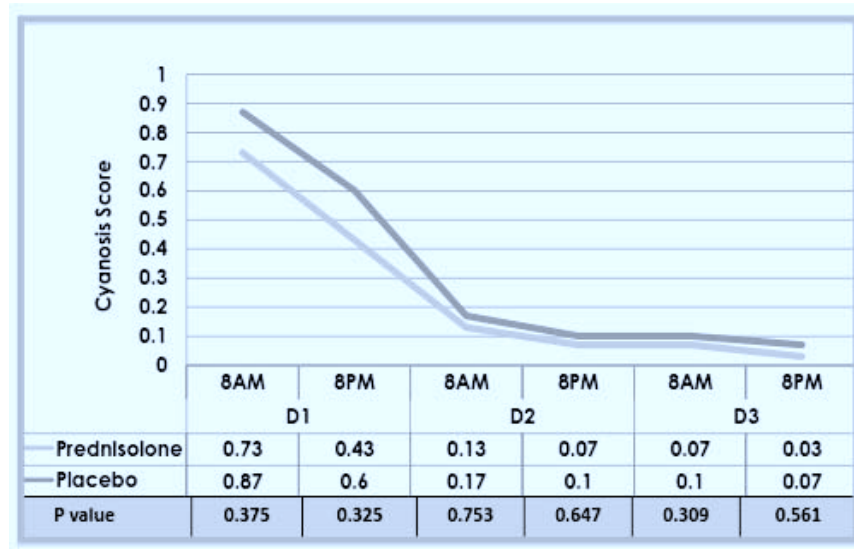

Mean duration of oxygen therapy and hospital stay were more in placebo group compared to prednisolone group $(p<0.01)$ [Table VI \& VII]

\section{Table VI : Comparison of duration of oxygen therapy} Duration of oxygen treatment(hours)

$\begin{array}{llllll}\text { Intervention } & \text { Mean(hrs) } & \text { SD } & \text { Range } & t & \text { P value } \\ \text { Prednisolone } & 13.70 & 6.727 & 5-30 & & \\ & & & & -4.183 & <.001\end{array}$

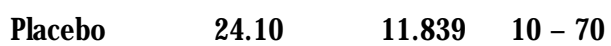

Table VII : Comparison of duration of Hospital stay Treatment Arm

$\begin{array}{llll}\text { Hospital stay (Days) } & \text { Prednisolone } & \text { Placebo } & \\ 3 \text { days } & 24(80.2 \%) & 5(16.7 \%) & \text { Chi sq }=26.7 \\ >3 \text { days } & 6(19.8 \%) & 25(83.3 \%) & P=.0001 \\ \text { Total } & \mathbf{3 0 ( 1 0 0 \% )} & \mathbf{3 0 ( 1 0 0 \% )}\end{array}$

\section{Discussion}

Acute bronchiolitis is the leading cause of hospitalization in children below 2 years of age. In this study male are predominantly affected in both groups, control groups with $53.3 \%$ and $66.7 \%$ respectively, however male-female distribution is statistically comparable in both the groups. Mean age of the patients affected with bronchiolitis in this series was 3.68 months $( \pm 1.29 \mathrm{SD})$ in prednisolone group and 3.52 months $( \pm 1.1 S D)$ in placebo group.

The clinical presentations of the patient in the study include cough, fast breathing, respiratory distress, chest indrawing and wheeze which were quite similar to what was observed in the study by Ahmed $A{ }^{7}$

In this study to determine treatment response patients were evaluated by modified Respiratory Distress Assessment Instrument score (mRDAl). Respiratory rate was found to decrease significantly $(p<0.01)$ in prednisolone group within 2 days. Ahmed A also observed similar improvement in fast breathing $(p<0.05)$ within 72 hours of treatment with oral prednisolone compared to placebo in his study. ${ }^{8}$

Use of accessory muscle which is a very good predictor for respiratory distress in children also showed significant improvement $(p<0.01)$ within 2 days of oral prednisolone therapy in this study which observation is comparable to what was found in the study by Klassen TP et al. ${ }^{9}$

In this study, duration of oxygen requirement was significantly lower in prednisolone group (13.7hrs) compared to placebo group(24.1hrs) and this difference was significant $(p<0.05)$ This finding is consistent with the observation of Klassen TP et al ${ }^{9}$

There was also marked decline in duration of hospital stay (3.3 vs 4.6days; $p<.01$ ) in prednisolone treated group. Similar shorter hospital stay was seen in another study by $C$ sonka $P$ et al. ${ }^{10}$

Khalid Alansari, et al. also found shortened time for discharge in bronchiolitic patients with eczema or a family history of asthma in a first-degree relative after treating with oral corticosteroid (Dexamethasone) in their study which may indicate that corticosteroid plays a positive role in treating atopy-prone bronchiolitis patient. ${ }^{11}$

In other study by von Woensen, et al. it was found that duration of hospital stay in mechanically ventilated bronchiolitis cases was shorter who were treated with prenisolone compared to those who didn't require mechanical ventilation but treated with prednisolone, the symptom score decreased significantly faster which finding is compatible to our study findings. ${ }^{12}$

\section{Conclusion}

Three days of oral prednisolone therapy along with supportive measures was found to be significantly useful among children with acute bronchiolitis having family history of atopy in terms of clinical recovery, oxygen requirement and duration of hospital stay.

\section{Recommendation}

Further multicenter research with larger sample size is recommended to provide information about benefits of steroids in acute bronchiolitis and also its role in atopy-prone children.

\section{References}

1. American Family Physician. March 1997; 55:1134-46.

2. Research article: Magnitude of respiratory disorders in under five children attending different hospitals of Bangladesh. Institute of child and mother health. March, 2009.

3. A H Mollah et al. Clinico-epidemiological study of acute bronchiolitis: Findings from Bangladesh'2012.

4. Fonseca Cde B, Grisi S. Bronchiolitis, respiratory syncytial virus, and recurrent wheezing: what is the relationship? Rev Hosp Clin Fac Med Sao Paulo. 2003 Jan-Feb; 58(1):39-48. Epub 2003 Apr 30

5. I Laing,et al. Atopy predisposing to acute bronchiolitis during an Epidemic of RSV. Bmj. 1982; vol-284:1070-172.

6. Donald Y. et al. Allergic and immunologic basis of atopy. Nelson paediatrics. $19^{\text {th }}$ ed. 2011.

7. Kabir AR, Mollah $\mathrm{AH}$, et al. Management of bronchiolitis without antibiotics: a multicentre randomized control trial in Bangladesh. Acta Paediatr. 2009 Oct; 98(10):1593-9.

8. Ahmed A. Efficacy of oral prednisolone in relieving hypoxia in children with acute bronchiolitis: A randomized double blinded placebo-controlled trial. MD thesis/ Shahjalal University of Science \& Technology, Sylhet, 2008.

9. Klassen TP, Sutcliff T, Watters LK, Wells GA, Alien UD, Li MM. Dexamethasone in salbutamol-treated inpatients with acute bronchiolitis. J Paediatrics 1997; 130:191-196

10. Csonka P, Kaila M, Laippala P, Iso-Mustajärvi M, Vesikari T, Ashorn P. Oral prednisolone in the acute management of children age 6 to 35 months with viral respiratory infection-induced lower airway disease: a randomized, placebo-controlled trial. J Pediatr. 2003 Dec; 143(6): 725-30

11. Khalid Alansari, Mahmoud Sakran, Bruce L. Davidson, Khalid Ibrahim, Mahmoud Alrefai and Ibrahim Zakaria. Oral Dexamethasone for Bronchiolitis: A Randomized Trial. Pediatrics 2013;132:e810-e816

12. Job B M van Woensel, TomFWWolfs, Wim M C van Aalderen, Paul L P Brand, J an L LKimpen Randomised double blind placebo controlled trial of prednisolone in children admitted to hospital with respiratory syncytial virus bronchiolitis. Thorax.1997; 52:634-637. 